\title{
Intraarticular Giant Size Angiolipoma of the Knee Causing Lateral Patellar Dislocation
}

\author{
Gökhan İlyas ${ }^{1}$, Ali Turgut ${ }^{1}$, Duygu Ayaz ${ }^{2}$, Önder Kalenderer ${ }^{1}$ \\ ${ }^{1}$ Department of Orthopaedics and Traumatology, Tepecik Training and Research Hospital, İzmir, Turkey \\ ${ }^{2}$ Department of Pathology, Tepecik Training and Research Hospital, İzmir, Turkey
}

Background: Angiolipomas are benign tumors usually seen in patients during their $2^{\text {nd }}$ and $3^{\text {rd }}$ decades. The subcutaneous region of the trunk, neck and extremities are the places where they generally settle. There is only one case report on angiolipoma in the knee joint that was resected by arthroscopic procedure in the English literature.

Case Report: We present a case of a giant-size multilobular non-infiltrating angiolipoma, extending outside of the right knee joint and causing lateral patellar dislocation in a thirteen-year-old boy. A large encapsulated mass with fatty and soft-tissue components on magnetic resonance imaging was suggestive of a liposarcoma. However, the diagnosis after the tru-cut biopsy was angiolipoma. The Quadriceps angle was $25^{\circ}$. Complete resection of the tumoral mass and repair of the medial retinaculum were performed with open surgery. Patellofemoral alignment was provided by transferring the tibial tuberosity medially. One year after the surgery, there was no evidence of recurrence.

Conclusion: Intra-articular angiolipomas are rarely seen masses in the knee joint. To our knowledge, this case report is the first to demonstrate that angiolipoma causes patellar dislocation.

Keywords: Angiolipoma, knee, patellar dislocation
Angiolipomas are benign tumors usually seen in patients during their $2^{\text {nd }}$ and $3^{\text {rd }}$ decades (1). They consist of mature adipose tissue and unusual vascular components. The subcutaneous region of the trunk, neck and extremities are the places where they generally settle. They may be visible in any part of the body (2). The most frequent settling place is particularly the forearm; almost two third of the angiolipomas are seen here (3). This is not the first case report on intra-articular angiolipomas of the knee (4), but this is the first reported case of intra-articular giant-size angiolipoma of the knee joint causing lateral patellar dislocation.

\section{CASE PRESENTATION}

A 13-year-old boy was admitted to our hospital with complaints of an expanding mass and anterior pain in his right knee. His medical history was: recurrent swelling, active extension disability of the right knee over a period of 6 months without trauma. Physical examination showed serious swelling of the supero-lateral side of the knee with irreducible lateral patellar dislocation. The passive range of motion of the knee was between $5^{\circ}$ extension deficient and $110^{\circ}$ flexion; however, active range of motion of the knee was between $30^{\circ}$ extension deficient and $100^{\circ}$ flexion. The quadriceps angle (QA) was $25^{\circ}$ with knee extension. Merchant's view demonstrated lateral dislocation of patella and decreased sulcus angle (Figure 1a). Our patient's sulcus angle was $120^{\circ}$ (normally is $140^{\circ}$ ). Radiographic views showed no degenerative changes on articular surface. Magnetic resonance imaging (MRI) showed a 15x9x8 $\mathrm{cm}$ giant size multilobulated tumor localized from inside out to supero-lateral side of the right knee joint (Figure 1b-d). Tumor's signal intensity was as same as normal subcutaneous adipose tissue. As there were rarely identified low signal heterogeneous areas, histopathological diagnosis was recommended. For this reason, we performed a tru-cut biopsy. Path- 

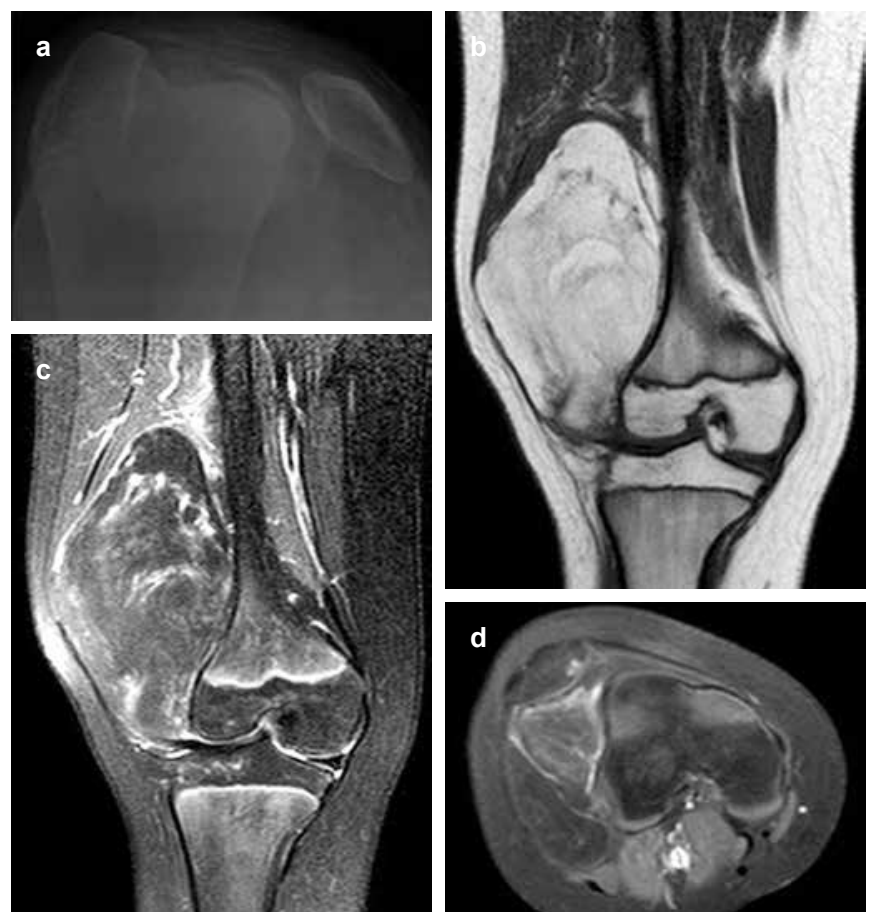

FIG. 1. a-d. Laterally dislocated patella (a). T1 TSE-weighted coronal MRI image of the tumor (b). T2-weighted fat-suppressed coronal MRI image of the tumor (c). T1-weighted fat suppressed with contrastenhanced axial view demonstrates the intraarticular localization of the tumoral mass $(d)$.
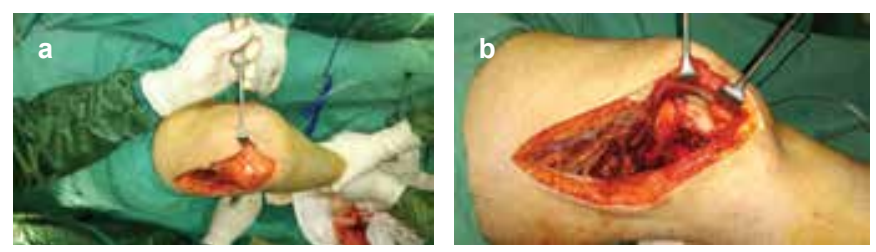

FIG. 2. a,b. Medial-lateral parapatellar incisions and intraoperative macroscopic view of the tumoral mass(a). After complete resection of the tumor (b).

ological biopsy diagnosis was angiolipoma. We performed complete resection of the tumoral mass and repair of medial retinaculum and plication of vastus medialis obliquus muscle with medial and lateral parapatellar exposures (Figure 2a). The macroscopic examination of the tumor was similar to lipoma and liposarcoma. After repairing medial and releasing lateral retinaculums, we found that patellar maltracking and lateral instability remained obvious. After complete resection of the tumoral mass (Figure 2b), we measured QA again with cautery cable and sterile goniometer; the result was $28^{\circ}$. So we performed medial transfer of tibial tuberosity (Elmslie-Trillat procedure) (5). Histological aspect of the excised tumor tissue revealed mature adipose cells with blood vessels and the final pathological diagnosis was angiolipoma (Figure 3a, b). After one year of follow-up, no evidence of recurrence of the tu-
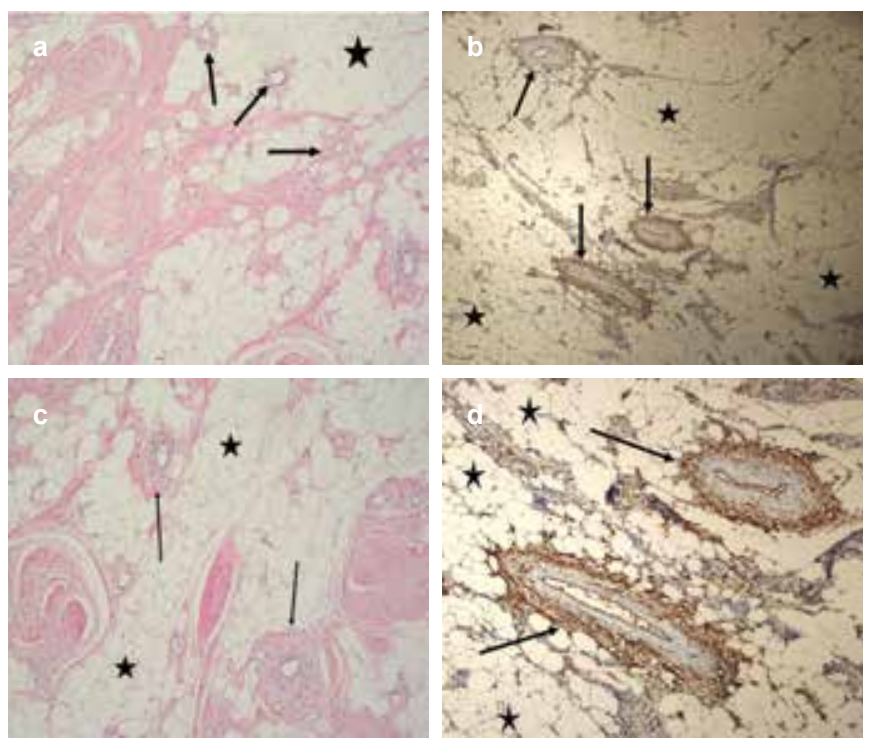

FIG. 3. a-d. Low power field view of the tumor histologically. Arrows: transvers section of vascular tissue, star: mature adipose tissue (hematoxylin/eosin staining) (a). Low power field view of the tumor histologically. Arrows: transvers section of vascular tissue, stars: mature adipose tissue (CD34 immunostaining). (b). High power field view of the tumor histologically. Arrows: transvers section of vascular tissue, stars: mature adipose tissue (hematoxylin/eosin staining) (c). High power field view of the tumor histologically. Arrows: transvers section of vascular tissue, stars: mature adipose tissue (CD34 immunostaining) (d).
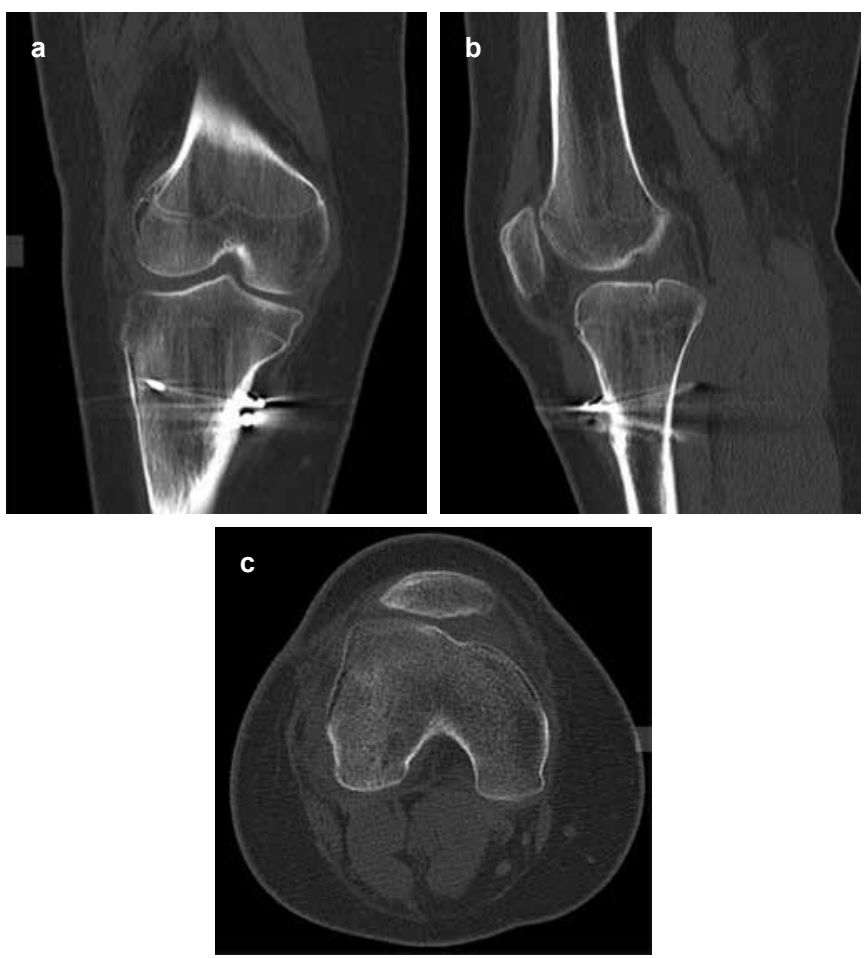

FIG. 4. a-c. Coronal computerized tomographic view of the knee after 1 year (a). Sagittal computerized tomographic view of the knee after 1 year (b). Axial computerized tomographic view of the knee after 1 year (c). 

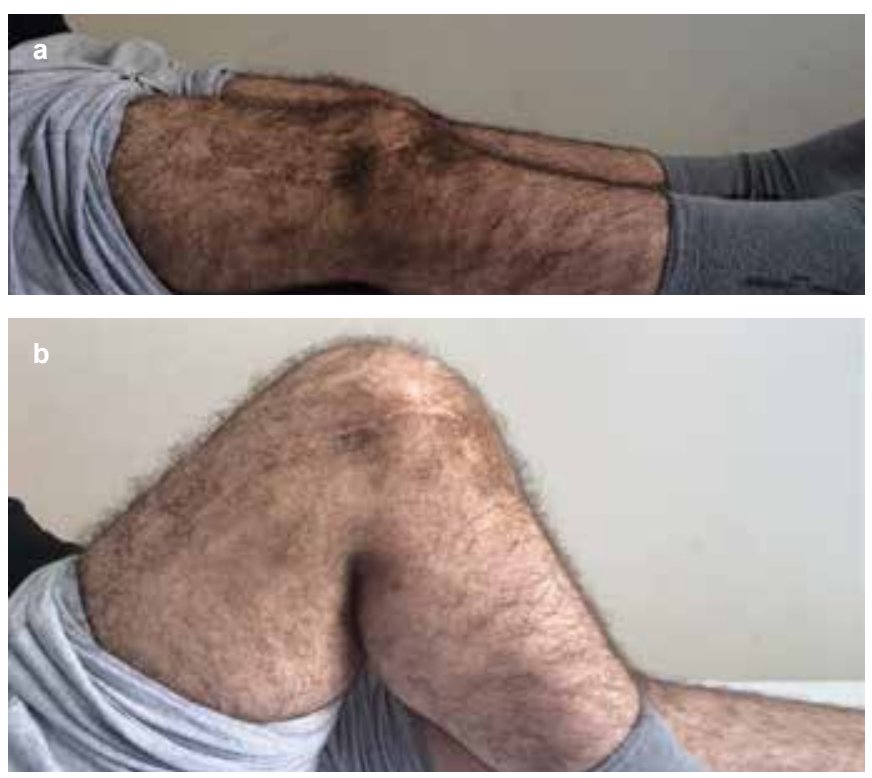

FIG. 5. a,b. Full extension of the knee had been achieved (a). Patient had gained $110^{\circ}$ of knee flexion (b).

moral mass and patellar instability was observed (Figure 4a-c). Range of motion of the knee was $110^{\circ}$ flexion and full extension, recurvatum deformity of the knee joint was not obvious. Our case had no limitations in daily living activities (Figure 5a, b). Written informed consent was obtained from the parent of the patient.

\section{DISCUSSION}

Angiolipoma is an uncommon tumor; it has its own histological characteristics, including mature fatty tissue and sprinkled proliferated vascular components. Angiolipomas comprise $5-17 \%$ of lipomas (6). It is mostly accepted by the authors that angiolipomas may be developed by embryonic sequestration of multipotential mesenchymal cells, and puberty activates this process via hormones (7). Nishimori et al. (4) first reported about intraarticular angiolipoma of the knee joint in 2010. They had performed arthroscopic resection of the $20 \times 20 \times 10$ millimeters sized tumoral mass. There is no other report about angiolipoma of the knee joint until this report. In our case, the size of the tumoral mass was $15 \times 9 \times 8 \mathrm{~cm}$. This mass effect caused the patella to be dislocated out from the trochlear groove.

Benign adipose tissue tumors can be seen in many conditions. For example, lipomas, lipomatosis, lipoblastoma, lipoblastomatosis, angiolipomas, and myolipomas are considered benign adipose tissue tumors (6). Angiolipomas show iso-hyperintensity on T1-weighted images and hyperinten- sity on T2-weighted images of magnetic resonance imaging (MRI), and most lesions develop with contrast medium administration (8). In the present case, the tumor's signal intensity is the same as normal adipose tissue, but low signal heterogeneous areas complicated the benign looking appearance. So we decided to perform a tru-cut biopsy to achieve histopathological diagnosis. Histologically, two predominant tissue elements are included in an angiolipoma: adipocytes and interspersed vascular structures. The vessels are small-caliber capillaries, and they frequently consist of fibrin thrombi, which is a typical feature of this lesion with surrounding mature fat (3). The tru-cut biopsy result had confirmed angiolipoma diagnosis. In our case, the tumoral mass was so large and it was extending outside of the knee joint that leads to dislocation of the patella laterally. So, we decided to perform an open surgery to resect the tumor and correct patellar-femoral alignment.

The patella remained unstable after resection of the tumor. In this case, proximal realignment procedures (lateral release and medial plication - augmentation) have to be the choice of surgical treatment in skeletally immature patients (9). The medial and lateral sides of the patella were opened already to explore and resect the tumor (Figure 2a). After the repair and plication of the medial structures, patellar maltracking was still obvious; so we had to perform medial transfer of tibial tubercule because the Q angle was increased, and we don't have any experience about trochleoplasty and medial transfer of the patellar tendon. One can criticize about performing the distal bony alignment procedure in a 13 year boy patient which can cause growth arrest of tuberosity apophysis and, finally, recurvatum deformity of the knee joint. However, this was our last chance to prevent patellar instability after performing proximal soft-tissue procedures.

In conclusion, we can state that intra-articular angiolipoma of the knee can cause knee pain. Delaying the treatment can lead to lateral dislocation of the patella if the angiolipoma is enlarged enough to cause such damage.

\section{Ethics Committee Approval: N/A.}

Informed Consent: Written informed consent has been obtained from the parent of the patient.

Peer-review: Externally peer-reviewed.

Author contributions: Concept - G.İ., A.T., Ö.K., D.A.; Design - G.İ., A.T., Ö.K. Supervision - Ö.K.; Resource - G.İ., A.T., Ö.K., D.A.; Materials - G.İ., D.A.; Data Collection and/or Processing G.İ., A.T., Ö.K., D.A.; Analysis and/or Interpretation - G.İ., A.T., Ö.K., D.A.; Literature Search - G.İ., A.T., Ö.K.; Writing - G.İ., A.T., Ö.K., Critical Reviews - Ö.K. 
Conflict of Interest: No conflict of interest was declared by the authors.

Financial Disclosure: The authors declared that this case has received no financial support.

\section{REFERENCES}

1. Nguyen L, Zwagerman NT, Grandhi R, McFadden K, Richardson RM. Intraosseous angiolipoma of the cranium: case report and review of the literature. Surg Neurol Int 2014;5:79. [CrossRef]

2. Ghanta RK, Koti K, Dandamudi S. Spinal epidural angiolipoma: A rare cause of spinal cord compression. J Neurosci Rural Pract 2012;3:341-3. [CrossRef]

3. Weiss SW, Goldblum JR. Enzinger and Weiss's soft tissue tumors. $4^{\text {th }}$ ed. St Louis: Mo: Mosby; 2001.
4. Nishimori M, Deie M, Adachi N, Kanaya A, Nakamae A, Ochi M. Intra-articular angiolipoma of the knee: a case report. Sports Med Arthrosc Rehabil Ther Technol 2010;2:10. [CrossRef]

5. Krämer K L, Jani L. The elmslie-trillat procedure. Orthop Trauma 1992;1:34-44. [CrossRef]

6. Kacar S, Kuran S, Temucin T, Odemis B, Karadeniz N, Sasmaz N. Rectal angiolipoma: a case report and review of literature. World J Gastroenterol 2007;13:1460-5. [CrossRef]

7. Howard WR, Helwig EB. Angiolipoma. Arch Dermatol 1960;82:924-31. [CrossRef]

8. Leu NH, Chen CY, Shy CG, Lu CY, Wu CS, Chen DC, et al. MR imaging of an infiltrating spinal epidural angiolipoma. AJNR Am J Neuroradiol 2003;24:1008-11.

9. Vavken P, Wimmer MD, Camathias C, Quidde J, Valderrabano V, Pagenstert G. Treating patella instability in skeletally immature patients. Arthroscopy 2013;29:1410-22. [CrossRef] 